$3^{\circ}$ INTEGRAR - Congresso Internacional de Arquivos,

Bibliotecas, Centros de Documentação e Museus

"PRESERVAR PARA AS FUTURAS GERAÇÕES"

\title{
Práticas culturais acessíveis - memorial da inclusão: os caminhos da pessoa com deficiência
}

\section{Carla Grião \\ Gabrielle Silva Carvalho}

Eixo Temático: Acessibilidade e inclusão

Palavras-Chave: Memorial da inclusão. Direitos da pessoa com deficiência. Acervo sobre o movimento social da pessoa com deficiência. Exposição acessível.

\section{Resumo expandido}

O Memorial da Inclusão: Os Caminhos da Pessoa com Deficiência surgiu em 2009 a partir da exposição em comemoração ao dia Internacional da Pessoa com Deficiência, na sede da Secretaria de Estado dos Direitos da Pessoa com Deficiência, localizada no complexo do Memorial da América Latina.

A exposição foi concebida e criada a partir de documentos e fotografias que foram emprestados pelas pessoas que fizeram parte da luta e das reinvindicações pelos direitos e inclusão social.

Atualmente, o Memorial da Inclusão tornou-se um espaço expositivo, no qual contempla diversas ações, tais como: oferece espaço para exposições temporárias (com recursos acessíveis) e para ensaios artísticos e oficinas; promove mediação para crianças, adolescentes, professores e o público em geral. E objetivando resgatar a história do Movimento Social das Pessoas com Deficiência está com o projeto para desenvolver o acervo documental, em parceria com Arquivo Público do Estado de São Paulo. 
$3^{\circ}$ INTEGRAR - Congresso Internacional de Arquivos,

Bibliotecas, Centros de Documentação e Museus

"PRESERVAR PARA AS FUTURAS GERAÇÕES"

Além disso, há o projeto Memórias, que registra e divulga narrativas de lideranças e participantes do movimento das pessoas com deficiência. Algumas dessas narrativas, acrescidas de outras, fazem parte do documentário Da invisibilidade à cidadania: os caminhos da pessoa com deficiência, produzido, em 2014, pelo Memorial da Inclusão, em parceria com a Fundação Padre Anchieta - TV Cultura.

Como o Memorial da Inclusão possui uma série de ações que visam o protagonismo das pessoas com deficiências e a conscientização da sociedade em relação aos direitos dessa parcela da população, concentraremos a nossa apresentação no III Integrar em duas ações: o desenvolvimento do acervo referente à história e memória do Movimento Político e Social da Pessoa com Deficiência no Brasil e as exposições temporárias que rediscutem as temáticas e trazem novos olhares.

\section{Introdução}

Memorial da Inclusão: os Caminhos da Pessoa com Deficiência é o título de uma Exposição de caráter permanente, sediada no andar térreo da Secretaria de Estado dos Direitos da Pessoa com Deficiência (SEDPcD). O projeto da Exposição foi aprovado em 2009 pelo Governo do Estado de São Paulo por meio da Secretaria, contemplada como ação relativa à promoção da realização dos estudos, debates e pesquisas sobre a vida e a realidade da pessoa com deficiência e seus familiares e à conscientização dos diversos setores da sociedade sobre problemas, necessidades, potencialidades e direitos das pessoas com deficiência (conforme Decreto $n^{\circ} \mathbf{5 2 . 8 4 1}$, de 27 de março de 2008, incisos VIII e X do Art. 3º). A Exposição é formada por doze painéis assinados pelos colaboradores (militantes), com temas que se interpenetram para compor os caminhos. 
$3^{\circ}$ INTEGRAR - Congresso Internacional de Arquivos,

Bibliotecas, Centros de Documentação e Museus

"PRESERVAR PARA AS FUTURAS GERAÇÕES"

Com o decorrer dos anos, a exposição permanente se tornou um espaço de cultura e informação, no qual desenvolve ações, dentre elas: oferecimento do espaço para exposições temporárias, de modo que o expositor sugere, organiza, cria e executa uma exposição que dialogue e desmembre a abordagem da permanente, baseada no conceito de curadoria inversa. Desta forma, visa incentivar práticas de acessibilidade inovadoras e condizentes com as condições do expositor, de modo a refletirmos acerca da adaptação razoável e da reabilitação baseada na comunidade (CROSARA; VITAL, 2008).

Outro eixo de atuação do Memorial é o desenvolvimento do Acervo Documental referente à história e memória desse movimento, que ganhou força e visibilidade a partir do Ano Internacional da Pessoa com Deficiência (AIPD) lançado pela ONU em 1981, que atingiu desde então importantes conquistas na garantia de direitos na educação, saúde, cultura, lazer, dentre outros. As mobilizações não eram apenas pelos direitos e cidadania, mas também, uma maneira de dar visibilidade a um segmento excluído, colocado à margem da sociedade. "O movimento social das pessoas deficientes mudou e continua mudando a forma como a sociedade brasileira vê, entende e convive com a deficiência" (CRESPO; 2009, p.21).

O acervo é composto por documentos doados por pessoas físicas, sociedade civil organizada e instituições públicas ou privadas. Visto que, as fontes históricas atas, jornais e boletins de organizações, folhetos de convocação de manifestações, publicações, filmes, fotografias - estão espalhadas, muitas vezes em posse de personagens dessa história, indivíduos que participaram e ainda participam da luta pelos direitos das pessoas com deficiência (LANNA JUNIOR, 2010).

O Arquivo Público do Estado de São Paulo será responsável pela guarda permanente dos documentos físicos e o Memorial da inclusão disponibilizará o acervo em meio virtual com recursos de acessibilidade. 
$3^{\circ}$ INTEGRAR - Congresso Internacional de Arquivos,

Bibliotecas, Centros de Documentação e Museus

"PRESERVAR PARA AS FUTURAS GERAÇÕES"

\section{Relato da experiência}

Como o objetivo primordial do Memorial da Inclusão é a conscientização sobre os direitos da pessoa com deficiência e contribuir para o empoderamento e o protagonismo desta parcela da população, realiza uma série de atividades a fim de naturalizar a questão da deficiência e auxiliar na inclusão social.

A exposição permanente do Memorial da Inclusão agrupa fotografias, documentos, manuscritos, áudios e vídeos sobre os personagens e eventos que marcaram o movimento social e político das pessoas com deficiência em defesa de seus direitos, no contexto maior dos direitos humanos. E dispõe de um ambiente temático complementar, a Sala dos Sentidos, um espaço sensorial desprovido de iluminação, com objetos e texturas distribuídos ao longo das paredes. Além dos objetos, a sala possui sons, onde os visitantes são convidados a experimentar e refletir sobre os sentidos (tato, visão, audição).

Com as exposições temporárias, há o desdobramento dos temas abordados na permanente. A ação educativa, através de mediação junto às exposições (permanente e temporária) para grupos agendados e visitantes espontâneos, reverbera-se discussões e reflexões acerca dos conceitos trabalhados. Também, por meio de projeção de vídeos, atividades lúdicas e palestras, fomentamos debate sobre os seguintes temas: inclusão social, acessibilidade, exclusão, diversidade humana, direitos humanos, direitos da pessoa com deficiência, desenho universal, entre outros.

Para atender ao público, a exposição oferece diversos recursos de acessibilidade. Para as pessoas cegas ou com deficiência visual, há piso tátil, material em braile, tipos ampliados e áudio, através de tubos sonoros acionados por sensor de presença. Para pessoas com deficiência auditiva e surdas, além das visitas agendadas 
$3^{\circ}$ INTEGRAR - Congresso Internacional de Arquivos,

Bibliotecas, Centros de Documentação e Museus

"PRESERVAR PARA AS FUTURAS GERAÇÕES"

poderem ser acompanhadas por mediador versado na língua brasileira de sinais, o conteúdo textual expositivo é acompanhado com vídeolibras e os vídeos presentes na exposição são legendados. Para pessoas com mobilidade reduzida e com deficiência física, o acesso ao Memorial da Inclusão possui rampas e o espaço de circulação externo e interno é plano. Há elevadores e sanitários adaptados. Para público com deficiência intelectual, a mediação é realizada com base na leitura facilitada, que adapta o discurso expositivo para uma linguagem mais lúdica e sensível.

O projeto do acervo iniciou as atividades efetivamente em 2015, com a montagem da reserva técnica para guarda temporária e tratamento documental. Atualmente, possuímos cinco conjuntos documentais doados por militantes. Como o projeto está em fase inicial - processo de triagem, higienização e identificação dos documentos - finalizamos nesse primeiro momento o processo de incorporação, pois há documentos que terão vários exemplares em conjuntos documentais diferentes.

Além disso, assim que é realizada a doação, o militante assina um termo de doação transferindo todos os direitos ao Memorial da Inclusão/Secretaria dos Direitos da Pessoa com Deficiência. E também é feita uma gravação para nos auxiliar no entendimento do contexto dos documentos com a temática do acervo.

A metodologia utilizada é baseado no método elaborado por Ana Maria de Almeida Camargo e Silvana Goulart utilizada na Fundação Fernando Henrique Cardoso. Esse método consiste na organização do acervo por funcionalidade, ou seja, estabelecimento de elo entre o documento e a atividade que the deu origem.

Esse projeto terá duas fases: a primeira consiste na formação e organização do acervo físico e após essa etapa será transferido para o Arquivo Público do Estado de São Paulo. Já a segunda, é a disponibilização do acervo em meio virtual, com finalidade de facilitar o acesso e disseminação dos direitos da pessoa com deficiência. 
$3^{\circ}$ INTEGRAR - Congresso Internacional de Arquivos,

Bibliotecas, Centros de Documentação e Museus

"PRESERVAR PARA AS FUTURAS GERAÇÕES"

\section{Considerações finais}

O Memorial da Inclusão: Os Caminhos da Pessoa Com Deficiência que teve início como uma Exposição sobre a história do Movimento Social da Pessoa Com Deficiência, hoje constitui um conjunto de ações e atividades que visam à democratização da cultura e informação, já que estes são direitos constitucionais. Por isso, oferece produtos culturais acessíveis e ações que visam à conscientização e sensibilização dos direitos da pessoa com deficiência. Ou seja, proporcionando equiparação de oportunidades, fomentando as discussões sobre a temática e, principalmente, contribuindo para uma sociedade mais inclusiva.

\section{Referências}

CRESPO, Ana Maria Morales. Da invisibilidade à construção da própria cidadania: Os obstáculos, as estratégias e as conquistas do movimento social das pessoas com deficiências no Brasil, através das histórias de vida de seus líderes. 2009; 399 p. (Tese Doutorado) Escola de Comunicações e Artes, Universidade de São Paulo. São Paulo, 2009.

CROSARA, Ana Paula de Resende; VITAL, Flavia Maria de Paiva (Coordenação). A Convenção sobre Direitos das Pessoas com Deficiência comentada. Brasília: Secretaria Especial dos Direitos Humanos, 2008.

GADELHA, C.; BUSTAMANTE, M. Memorial da Inclusão: Os caminhos da pessoa com deficiência. In. Anais do XXVI Simpósio Nacional da Historia- ANPUH. São Paulo, 2011, s/p.

LANNA Júnior, Mário Cléber Martins (Comp.). História do Movimento Político das Pessoas com Deficiência no Brasil. - Brasília: Secretaria de Direitos Humanos. Secretaria Nacional de Promoção dos Direitos da Pessoa com Deficiência, 2010.

SÃO PAULO (Estado). Decreto o 52.841, de 27 de março de 2008. Organiza a Secretaria de Estado dos Direitos da Pessoa com Deficiência e dá providências correlatas. Disponível em: http://governo-sp.jusbrasil.com.br/legislacao/93641/decreto52841-08. Acesso: 20/04/2016 
$3^{\circ}$ INTEGRAR - Congresso Internacional de Arquivos, Bibliotecas, Centros de Documentação e Museus "PRESERVAR PARA AS FUTURAS GERAÇÕES"

Informações das autoras

\section{Carla Grião}

\section{Gabrielle Silva Carvalho}

Memorial da Inclusão/Secretaria dos Direitos da Pessoa com Deficiência gabrielle_sc@ig.com.br

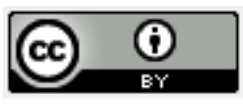

